\title{
Neodesenvolvimentismo, neoliberalismo e a correlação de forças nos governos Lula e Dilma
}

\author{
New developmentism, neoliberalism and the correlation of \\ forces in the Lula's and Dilma's governments
}

\author{
Marco Antonio Bestetti Paccolaa, Giovanni Antonio Pinto Alves ${ }^{b}$
}

\begin{abstract}
Resumo O artigo visa analisar o modelo político-econômico neodesenvolvimentista, buscando desnudar a correlação de forças que possibilitou sua implantação e que levou a mudanças significativas no contexto nacional. Procuramos relacionar a política econômica do governo, ao longo dos últimos anos, com os movimentos das frações da classe dominante brasileira, a conjuntura internacional e o desempenho econômico que tem influenciado diretamente estas políticas. Assim, busca-se demonstrar que a política nacional foi determinada, neste período, principalmente pela disputa entre setores da classe dominante. Disputa esta que se realizou devido à contestação da hegemonia neoliberal no Brasil, sustentada pela fração financeira e que passou a ser contrabalanceada por uma política neodesenvolvimentista, que buscou, no governo federal e na cooptação das classes subalternas, romper com o domínio dos setores financeiros. Esta disputa leva o país a uma crise política de grandes proporções, que culminou na queda do governo Dilma e na erosão do neodesenvolvimentismo.
\end{abstract}

Palavras-chave Neoliberalismo; Neodesenvolvimentismo; Lulismo; Luta de classes.

Abstract The papper aims to analyze the political-economic neodevelopmental model, seeking to unveil the correlation between forces that allowed its implementation and that led to significant changes in the national context. We have tried to relate the government's economic policy over the last few years to the movements of fractions of the Brazilian ruling class, the international situation and the economic performance that has directly influenced these policies. Thus, it is tried to demonstrate that the national politics was determined, in this period, mainly by the dispute between sectors of the dominant class. This dispute was made due to the contestation of the neoliberal hegemony in Brazil, supported by the financial fraction and which

a Doutorando em Ciências Sociais na Universidade Estadual de Campinas (Unicamp), professor da Universidade Estadual do centro oeste (Unicentro).

b Professor livre-docente da Universidade Estadual Paulista (Unesp) e do programa de doutorado em ciências sociais da Universidade Estadual de Campinas (Unicamp). 
was counterbalanced by a neodevelopmental policy, which sought, in the federal government and the co-optation of the subaltern classes, to break with the dominance of the financial sectors. This dispute leads the country to a major political crisis, which culminated in the fall of the Dilma government and the erosion of new developmentism. Keywords Neoliberalism; New developmentism; Lulismo; Class struggle.

\section{INTRODUÇÃO}

A ruptura do modelo desenvolvimentista em fins da década de 1980 e a emergência do neoliberalismo como modelo de desenvolvimento em substituição ao seu predecessor, a partir da década de 1990, estabeleceu uma nova conjuntura político-econômica para o Brasil. Durante o período seguinte, o modelo neoliberal foi edificando sua hegemonia sobre as classes no Brasil de modo a consolidar sua dominação (BOITO JR, 2003, p. 3). Contudo, ao longo dos últimos anos, observou-se um conjunto de políticas estatais que podem indicar um "desvio" ou afrouxamento dessa hegemonia neoliberal. O que levanta a indagação sobre a possibilidade de uma erosão da hegemonia neoliberal no país e uma reformulação do modelo de desenvolvimento nacional.

O acirramento da disputa se deu a partir da eleição de Luis Inácio Lula da Silva e do Partido dos Trabalhadores para o Governo Federal em 2002 (BRESSER-PEREIRA; DINIZ, 2009, p. 99). Apesar do longo processo de cooptação deste partido, observável nas campanhas eleitorais que precederam sua vitória (1989, 1994, 1998) e que garantiu a adesão do partido ao projeto político das classes dominantes (BOITO JR, 2003, p. 5), inclusive tornando possível sua vitória nas urnas, a eleição do PT abriu um novo período para a política-econômica nacional.

\section{NEODESENVOLVIMENTISMO E A CORRELAÇÃO DE FORÇAS NOS GOVERNOS LULA E DILMA}

Sem romper com os alicerces fundamentais do modelo neoliberal, durante os mais de 13 anos em que esteve no governo, o PT passou gradativamente a aglutinar as disputas entre duas correntes, o neoliberalismo, que permaneceu como projeto hegemônico na política brasileira, mas que passou a conviver com uma política menos rígida aos seus fundamentos, sintetizada no que convencionou chamar corrente neodesenvolvimentista.

De forma geral, o governo manteve o rumo da política-econômica que vinha sendo implementada no Brasil desde a década de 1990. Assim, herdando a diretriz econômica consolidada com o Plano Real de 1994 e mantida até 2002 pelos governos de Fernando Henrique Cardoso, o Partido dos trabalhadores moldou 
seu projeto político à esta herança, de modo a não realizar grandes alterações de conjuntura. Estas diretrizes neoliberais estão expressas em princípios que se tornariam objetivos declarados do partido a partir de então, como o Superávit primário, controle da inflação, autonomia do Banco Central, política cambial e de juros atreladas à estabilidade inflacionária, manutenção do pagamento da dívida pública, reforma da previdência, entre outros (BOITO JR, 2003).

Contudo, apesar da manutenção e até mesmo intensificação das políticas neoliberais, passariam a figurar no programa de governo um conjunto de políticas econômicas e sociais que não constavam nos governos anteriores e que estão relacionadas à nova orientação neodesenvolvimentista que se consolidava entre setores da classe dominante brasileira neste período, principalmente a burguesia produtivista (BOITO JR, 2013, p. 174). Dessa forma, caminhou-se no sentido da redução da taxa básica de juros, apesar dessa manter-se em níveis anacrônicos com a economia nacional, da participação ativa do Estado na indução de investimentos, principalmente em setores de infraestrutura e da implantação de políticas protecionistas para o mercado interno. Caminho que foi aprofundado no mandato de Dilma Rousseff a partir de 2011, levando inclusive à redução do superávit primário e dos spreads bancários, pilares da política econômica neoliberal. O que se observou, portanto, nos governos do PT, foi o fortalecimento da orientação neodesenvolvimentista para a política nacional, que, contudo, não pressupõe a ruptura do ciclo neoliberal no país, mas condiciona a ela um conjunto de medidas que beneficiam outros setores da burguesia, além dos tradicionalmente atendidos pelas políticas neoliberais:

Essa ascensão do neodesenvolvimentismo mostra que a política de Estado sob os governos petistas tem direção clara e visa ao desenvolvimento capitalista sem, no entanto, romper com alguns pilares do modelo neoliberal - citemos a rolagem da dívida pública, que inibe a capacidade de investimento do Estado, e a abertura comercial, que mina a indústria interna. (BOITO JR, 2013, p. 174)

Além dos "desvios" em relação à orientação neoliberal no plano econômico, essa orientação passaria a conviver também, num sentido antagônico, com políticas que contradizem ou não fazem parte do modelo neoliberal, entre elas: $\mathrm{o}$ aumento real do salário mínimo e políticas de assistência social com grande impacto econômico como o programa Bolsa Família (SINGER, 2012, p. 162). O que caracterizaria certa ruptura com o projeto neoliberal, que, apesar de não significar uma quebra 
de hegemonia, pode apontar para o reordenamento da correlação de forças na sociedade brasileira neste período.

O modelo desenvolvido pelo PT como resultado da correlação de forças que se materializou no período foi responsável, portanto, por um duplo redirecionamento da política nacional, primeiro por vincular ao programa neoliberal uma rede de proteção social com intuito de reduzir os altos índices de miséria e pobreza enfrentados pelo país e uma política de expansão da renda que apesar do ritmo ameno, se mostrou constante. E segundo, por beneficiar através da política econômica, outros setores da burguesia, neste caso nacional, que obtiveram ganhos significativos com esta política, entre eles os setores produtivos como a indústria, o agronegócio exportador, o setor petrolífero entre outros.

Nesse sentido, é possível interpretar o período dos governos petistas, a partir de um conjunto de políticas, principalmente no âmbito econômico e social, que o caracterizaram ao longo de sua consolidação e que expressam, de forma latente, uma conjuntura de classes do Bloco no poder brasileiro (BOITO JR, 2013, p.175-178).

Ocorreu neste período uma série de transformações na correlação de forças da sociedade brasileira e que estão relacionadas diretamente à condução política do país. Na década de 1990 e durante o início dos anos 2000, o modelo neoliberal gozou de grande prestígio e aceitação por parte da classe dominante brasileira e, de modo geral, da sociedade (BALTAR, 2009). Dessa forma, as políticas neoliberais implantadas pelos governos Collor e FHC refletiram uma dada correlação de forças que, com poucas discrepâncias, apoiavam este modelo. Entretanto, a partir da segunda metade dos anos 2000, influenciado por uma série de transformações na conjuntura econômica e política, dentre as quais devem ser destacadas, o "boom" das exportações brasileiras de commodities, os baixos níveis de crescimento do PIB na década anterior, o crescimento das taxas de desemprego, a crise econômica em 2008 e a própria eleição do Partido dos Trabalhadores (PACCOLA, 2016), houve uma alteração nessa correlação de forças da sociedade.

Sem romper a hegemonia neoliberal, as dissonâncias a este modelo ganham força, dessa forma, observa-se, ainda no governo Lula, com o surgimento de diversas políticas focadas nos setores produtivos, como a Política Industrial, Tecnológica e de Comércio Exterior (PITCE) em 2004, o Plano de Aceleração do Crescimento (PAC) em 2007, a Política de Desenvolvimento Produtivo (PDP) em 2008 (PACCOLA, 2016: 193-201). Além das políticas sociais como o já citado Programa bolsa família. Esta orientação neodesenvolvimentista foi aprofundada no governo Dilma (BOITO JR, 2016, p. 156). 
Nesse sentido, é possível interpretar o lulismo como um modelo permeado por políticas antagônicas, uma vez que ele comporta a continuidade do receituário econômico neoliberal, enquanto realiza um projeto de redistribuição e de elevação dos rendimentos das camadas mais pobres da população e busca a retomada do crescimento econômico a partir de políticas neodesenvolvimentistas. Esse antagonismo, expresso na política econômica, e que se materializou no modelo lulista, é resultado da correlação de forças que se operou na sociedade brasileira e das disputas de classe no Bloco no poder, as quais configuraram o modelo político dominante do período.

Apesar da constatação de antagonismos, não podemos considerar o lulismo como um modelo de conciliação entre os interesses divergentes das classes dominantes e subalternas no capitalismo brasileiro, arbitradas pelo governo, como faz parecer, em alguns momentos, a análise de André Singer (SINGER, 2012, p. 169). Apesar da ambiguidade, e da existência de políticas compensatórias e redistributivas no lulismo, estes governos permanecem como representantes da classe dominante: "Os governos Lula e Dilma são governos burgueses, especificamente da grande burguesia interna. Não são árbitros entre as classes fundamentais e nem são governos do subproletariado". (BOITO JR, 2013, p. 178) Esta orientação torna-se evidente ao analisarmos o eixo estrutural da política econômica do governo durante seus treze anos de mandato, prevalecendo como dito anteriormente, as orientações neoliberais (PACCOLA, 2016, p. 166).

$\mathrm{O}$ conceito de bloco no poder, utilizado como forma de interpretar esta correlação de forças, não pressupõe a existência de um equilíbrio de forças entre as frações de classes em uma determinada sociedade. O que ele estabelece é a existência de um conjunto de frações dentro da classe dominante, dentre as quais, uma deve ocupar a posição hegemônica. E que, apesar das contradições entre estas frações, elas compartilham o interesse comum de preservação do modo de produção capitalista, sustentado na exploração econômica e na dominação política por parte da burguesia:

Ora, a noção de fusão não pode permitir pensar o fenômeno do bloco no poder. Este constitui de fato não uma totalidade expressiva com elementos equivalentes, mas uma unidade contraditória complexa com dominante. É aqui que o conceito de hegemonia pode ser aplicado a uma classe ou fração no interior do bloco no poder. Essa classe ou fração hegemônica constitui, com efeito, o elemento dominante da unidade contraditória das classes ou frações politicamente “dominantes”, que fazem parte do bloco no poder. (POULANTZAS, 1977, p. 232) 
Por isso mesmo, o modelo neoliberal permaneceu na posição hegemônica na sociedade brasileira durante o período, pois, apesar da intensificação das políticas neodesenvolvimentistas, a fração de classe que detém a hegemonia na política brasileira continua sendo a burguesia financeira. Nesse contexto, não são os interesses da classe dominante que estão sendo colocados em confronto pelos antagonismos da política econômica do governo, não são os interesses do subproletariado que se opõem ao modelo neoliberal (SINGER, 2012: 173), mas sim os pontos de divergência entre as frações presentes no bloco no poder, que, apoiados por cisões na hegemonia neoliberal, provenientes desta nova correlação de forças, tem levado a contradições no seio do Estado:

[...] a contradição principal que determinou a crise foi a contradição que opõe o conjunto do campo neoliberal ortodoxo à frente política neodesenvolvimentista. A contradição entre as classes trabalhadoras e a burguesia participou da crise na condição de contradição secundária. (BOITO JR, 2016, p. 158)

Contudo, isso não significa que as classes subalternas estão totalmente excluídas do direcionamento político do Estado. Sem desconsiderar este Estado como uma instituição da classe burguesa, concebido como aparelho de dominação, contudo não automatizado e inflexível às disputas de classe. Este deve ser entendido como uma "condensação material de uma relação de forças entre classes e frações de classe" (POULANTZAS, 1985, p. 148).

Nesse sentido, podemos entender os inegáveis ganhos que as classes subalternas, principalmente aquelas em situação de extrema precariedade na sociedade brasileira, obtiveram com o governo do PT, como efeito desta correlação de forças no seio do próprio Estado. A razão destes ganhos precisa ser ponderada de maneira mais detalhada, mas podemos apontá-las também como um conjunto de políticas compensatórias necessárias para cooptação das classes subalternas (BOITO JR, 2003, p. 22).

Partindo desta interpretação, os ganhos das classes subalternas estariam relacionados, em parte, às disputas no interior da classe dominante brasileira, que colocariam os setores neodesenvolvimentistas em disputa com os setores neoliberais, corrente hegemônica:

Na verdade a grande burguesia interna, nas suas disputas com a fração burguesa perfeitamente integrada ao grande capital financeiro internacional, converteu-se 
em força dirigente de uma ampla e heterogênea frente política que poderíamos denominar neodesenvolvimentista. (BOITO JR, 2013, p. 178)

No desenrolar desta disputa, o lulismo teria garantido o consentimento passivo das classes subalternas através de políticas públicas de incremento dos salários e redistribuição de renda, de um lado, enquanto assegurava o apoio dos sindicatos e órgãos de classe, através da cooptação de suas lideranças para posições chave na burocracia estatal e a concessão do controle de importantes fundos de pensão (BRAGA, 2012, p. 181). Contudo, esta hipótese nos parece insuficiente pra explicar a ambiguidade da política econômica do período, já que desconsidera, ou ao menos reduz, a influência das classes subalternas sob as determinações da política estatal. A explicação para esta ambiguidade parece-nos estar mais relacionada a uma complexa correlação de forças que se estabeleceu no período, da qual a disputa entre setores financeiros e produtivistas é o elemento principal, mas não único:

Embora ampla e contraditória na sua composição de classe, a frente política neodesenvolvimentista existe e atua como tal. [...] Foi assim em 2002 na eleição presidencial de Lula da Silva; em 2005, na crise política que ficou conhecida como "Crise do Mensalão" e chegou a ameaçar a continuidade do governo Lula; em 2006, na reeleição de Lula da Silva para a presidência da República, e novamente em 2010 na campanha eleitoral vitoriosa de Dilma Rousseff. Em todos os momentos críticos citados, a sobrevivência dos governos neodesenvolvimentistas esteve ameaçada e, em todos eles, importantes associações patronais, centrais sindicais, movimentos camponeses, movimentos populares por moradia bem como o eleitorado pobre e desorganizado apoiaram, com manifestações dos mais variados tipos ou simplesmente com o seu voto, os governos e as candidaturas Lula da Silva e Dilma Rousseff. (BOITO JR, 2012, p. 11)

Contudo, a partir de 2013, observou-se um gradativo realinhamento das frações de classe em torno do modelo, enquanto no período anterior, o neodesenvolvimentismo foi capaz de aglutinar diversos setores da burguesia nacional como a burguesia industrial e o agronegócio e ainda setores das classes subalternas ao seu projeto político. No período seguinte, a frágil aliança neodesenvolvimentista viria a erodir, fazendo eclodir uma crise política que se tornaria latente a partir da segunda eleição de Dilma Rousseff (2014) (SINGER, 2015, p. 61). A crise política iniciada em 2013 levou o governo a retroceder a política neodesenvolvimentista, 
que havia se intensificado no início da década, apontando para a ruptura do modelo e para uma nova reconfiguração da correlação de forças no Brasil.

\section{A CRISE DO NEODESENVOLVIMENTISMO E A REAFIRMAÇÃO DA IDEOLOGIA NEOLIBERAL}

Podemos identificar como ponto de ruptura do equilíbrio na correlação de forças que sustentou os governos do PT, o aprofundamento das políticas neodesenvolvimentistas a partir do primeiro governo Dilma (2011). Enquanto, nos governos Lula, os fundamentos da política macroeconômica neoliberal foram mantidos e inclusive aprofundados, o governo Dilma estabeleceu como meta o "combate" a estas políticas, seguindo a interpretação que as apontava como entraves ao desenvolvimento da economia.

O tripé macroeconômico ortodoxo (superávit primário, câmbio flutuante e meta de inflação) é constituído por esses três conceitos genéricos que, afinal, resultam em dois parâmetros e um único objetivo que interessam a uma coalizão política neoliberal formada por capitalistas rentistas e financistas.

[...]

Dilma Rousseff compreendeu desde o início a necessidade de rever a política do tripé. Ela é uma economista desenvolvimentista, e, em discurso de 20 de abril de 2012, por ocasião da formatura de novos diplomatas, declarou que para se desenvolver o Brasil precisa "equacionar as três amarras do país: taxa de juros alta, câmbio e impostos altos. (BRESSER-PEREIRA, 2013)

Este "ataque" à política econômica neoliberal ortodoxa suscitou uma forte resistência por parte dos setores financeiros, do rentismo, do capital internacional e de grupos políticos que representam estes setores, inclusive o PMDB, partido aliado do governo desde 2003. Apesar disso, o embate pendia para o lado governista, as taxas de popularidade da presidente eram elevadas, a economia crescia, as taxas de desemprego mantinham-se a níveis baixíssimos (SINGER, 2016: 37). Dessa forma, foi possível levar adiante uma política de redução dos juros e dos spreads, pilar da política econômica neoliberal.

Contudo, dois anos após o início da empreitada neodesenvolvimentista, a situação do governo se modificara profundamente, enfrentando uma enorme onde de protestos que teve inicio em 2013, fraco desempenho da economia, graves denúncias de corrupção de importantes membros do governo, queda nos índices 
de popularidade, e tendo a reeleição ameaçada, o ímpeto do governo em combater as políticas ortodoxas dava sinais de esmorecimento (SINGER, 2016, p. 40).

A partir da reeleição da presidente Dilma em 2014, os recuos na política neodesenvolvimentista foram constantes, elevação dos juros, redução da intervenção estatal na economia, corte de investimentos públicos, cortes orçamentários, em suma, o governo seguiu a risca a aplicação da política ortodoxa neoliberal. Apesar deste recuo, a crise política e o processo de afastamento da presidente e do PT já haviam avançado, culminando no impeachment de Dilma em 2016:

[...] grandes setores do capital querem restaurar a hegemonia do neoliberalismo; aqueles que apoiaram a estratégia nacional de desenvolvimento do PT agora o abandonaram, a mídia está uivando tão alto que se tornou impossível pensar com clareza e a maior parte da classe média alta despencou em um ódio fascista contra o PT, a esquerda, os pobres e os negros"'. (SAAD FILHO, 2016)

O período entre o inicio da empreita neodesenvolvimentista, ao final de $2011 \mathrm{e}$ o impeachment em 2016, foi palco de uma reconfiguração na correlação de forças no país, que resultou na reafirmação da hegemonia neoliberal e foi responsável, segundo nossa análise, pela reformulação da política econômica. As causas, os fatores, os condicionantes deste processo é o que procuraremos apontar a seguir.

\section{POSSÍVEIS CAUSAS PARA O COLAPSO NEODESENVOLVIMENTISTA (A TÍTULO DE CONCLUSÃo)}

A reversão da conjuntura político-econômica nacional, coroada com o impeachment da presidente, parece indicar que o modelo neodesenvolvimentista esgotou-se. Nesse sentido, a crise política seria reflexo do reordenamento das frações de classe no Bloco no poder e de um reordenamento na correlação de forças entre as classes, às quais deixaram de apoiar o governo, como ocorrera em períodos anteriores. A crise política não nos parece constituir a causa de esgotamento do modelo, contudo ela acentuou o processo, ao minar o modelo político sobre o qual se estruturou o neodesenvolvimentismo neste período, o modelo lulista, de

1 Texto original em inglês: "Large sections of capital want to restore the hegemony of neoliberalism; those who once supported the PT's national development strategy have fallen into line; the media is howling so loudly it has become impossible to think clearly, and most of the upper-middle class has descended into a fascist odium for the PT, the left, the poor, and blacks." (tradução do autor). 
modo a ruir as bases sobre as quais o PT estruturou sua política nos últimos anos, deixando o partido sem condições de sustentar sua posição no governo.

Contudo, consideramos que os fatores determinantes para esta ruptura não estão dados apenas pela conjuntura política. As razões que levaram os setores antes comprometidos com o governo a romper com a plataforma neodesenvolvimentista precisam ser analisados de forma a apontar os limites e contradições que decretaram a erosão do modelo. Deste modo, podemos apontar algumas hipóteses sobre as causas do reordenamento da correlação de forças entre as classes e frações de classe no período.

Em primeiro lugar é preciso destacar o processo de aproximação do PT à fração hegemônica no bloco no poder do país, ou seja, o setor financeiro. Ao longo da década de 1990 ocorre uma gradual aproximação do partido às classes dominantes e a gradual interiorização no partido do projeto político hegemônico. Que tem como objetivo viabilizar o partido, como possível representante da classe dominante na política nacional. Este movimento foi realizado ao longo de vários anos, e não corresponde a mudanças restritas apenas à orientação política dos líderes do partido, mas sim a um processo de reorientação ideológica do partido como um todo.

Agora, é importante destacar uma ideia geral: ocorreu um processo político e social no Brasil ao longo dos anos 90 que resultou na implantação de uma nova hegemonia burguesa em nosso país, baseada no discurso e na prática do modelo capitalista neoliberal dependente. Colocado o problema dessa forma, a "conversão" do PT ao credo do livre mercado aparece como mais um episódio - ainda que sem dúvida um episódio de importância maior - nesse processo de implantação e consolidação da nova hegemonia burguesa. (BOITO JR, 2003, p. 4)

Ao aproximar o partido do projeto político hegemônico neoliberal, através da cooptação de suas lideranças e das alianças estabelecidas com representantes desta fração de classe, entre eles o próprio PMDB, principal partido aliado do governo, o PT estabeleceu laços profundos com a fração financeira da burguesia. Essas relações ficaram evidenciadas na política econômica adotada pelo partido ao longo dos seus mandatos, com exceção do segundo governo Dilma, em nenhum momento houvera a contestação do domínio financeiro sobre a política econômica e os interesses deste setor foram privilegiados pelos governos petistas. 
Contudo, esta amálgama com o capital financeiro estabelecia rígidos limites à política econômica petista, dada a própria composição da base de apoio do partido, dentro da classe dominante, sua política ficava restrita aos interesses deste grupo.

Dessa forma, os limites do modelo neodesenvolvimentista estariam dados pela própria composição de forças que se formou no governo neste período e que dava sustentação ao partido. Tratava-se de um projeto assentido pelo setor hegemônico da classe dominante, desde que não interferisse nos seus interesses diretos. Assim, quando este projeto ameaçou molestar tais interesses, o consentimento se desfaz e os setores que representam tais interesses dentro do governo, iniciam uma ofensiva contra o projeto e, posteriormente, contra o próprio governo.

Ademais, podemos relacionar ao conjunto de fatores que contribuiu para o equilíbrio da correlação de forças que sustentou o neodesenvolvimentismo, a conjuntura internacional. O "boom" das commodities, o crescimento econômico chinês e o cenário externo profundamente favorável, teriam gerado um redirecionamento no padrão de desenvolvimento nacional, tornando possível a aplicação de uma política voltada para os setores produtivistas. Com a reversão deste cenário, a partir da crise econômica de 2008, agravada no Brasil em 2011, as condições para a manutenção do modelo neodesenvolvimentista foram esvaindo-se, apesar dos esforços do governo, levando à sua ruptura.

A reversão deste cenário influencia diretamente as disputas entre as frações de classe no bloco de poder no Brasil, a burguesia financeira aliada ao capital internacional e a burguesia nacional produtivista. Essa disputa é desequilibrada em função do enfraquecimento dos setores produtivistas, como consequência do cenário internacional, o que culminou na crise política e econômica que erodiu modelo neodesenvolvimentista.

O argumento que desejamos fixar é que a durabilidade do lulismo não depende exclusivamente das condições externas. [...] Em outras palavras, o sucesso do lulismo pode vir a depender do resultado da disputa entre as coalizões produtivista e rentista descrita no capítulo 3 , e não da conjuntura internacional. (SINGER, 2012, p. 152)

Ademais, a fragilidade do modelo neodesenvolvimentista estaria na própria composição de classes que o sustentou, gerando um equilíbrio instável na correlação de forças. A aliança entre setores, os mais diversos, contava com limitações estruturais. Em primeiro lugar, as contradições entre a fração de classe dominante e as classes subalternas que apoiavam o modelo levariam, cedo ou tarde, a um 
conflito interno no grupo. As políticas de aumento real do salário, redistribuição de renda e expansão do emprego empoderaram a classe trabalhadora, dando melhores condições de participação na luta de classes, o que desagradou a fração dominante do grupo, levando ao seu gradativo afastamento (SINGER, 2015, p. 65). Em segundo lugar, a composição orgânica da fração produtivista coloca limites ao apoio desta classe ao modelo. Isso porque, ao mesmo tempo em que tem seu capital vinculado ao setor produtivo, esta fração possui capital investido no setor financeiro, de modo que, seus interesses estão ao mesmo tempo em contradição e sintonia com a fração financeira, já que ela mesma é, em parte, rentista.

A dupla condição dos industriais restringiria o grau de empenho na plataforma produtivista. Como capitão de indústria, deseja crédito barato, portanto, redução dos juros. Todavia, como proprietário de conglomerado que é também financeiro, aspira a juros altos, que remunerem o dinheiro aplicado. (SINGER, 2015, p. 65)

Fato que coaduna com argumento que relaciona a ruptura do neodesenvolvimentismo à conjuntura externa, visto que, durante o período em que os ganhos no setor produtivo puderam ser potencializados pelo cenário internacional, a fração da burguesia, que conserva capitais tanto no setor financeiro quanto no setor produtivo, defendeu o aprofundamento de seus ganhos através de políticas voltadas para este setor. Porém, dada a reversão da conjuntura externa, esta fração deixa de apoiar as políticas neodesenvolvimentistas, tendendo ao setor financeiro. Isso explica também, porque as contestações do setor produtivista concentraram-se em aspectos específicos da política-econômica, principalmente a taxa de juros, sem realizar um questionamento contundente acerca de outras questões estruturais do modelo neoliberal.

Isoladamente, os fatores apontados acima, a despeito da crise do modelo neodesenvolvimentista, não são capazes de explicar o fenômeno como um todo, é preciso que relacionemos tais aspectos para compreender o movimento de ruptura obsevado na base de apoio do governo a partir de 2012. Contudo, entendemos que a crise política sobre a qual erodiu o modelo neodesenvolvimentista brasileiro e que levou, por conseguinte, ao golpe de 2015, encontra suas origens na disputa entre os setores da classe dominante acerca do projeto político-econômico adotado. Tendo em vista que, ao se extinguirem as condições de continuidade da política econômica ambígua, que marcou os governos petistas e que tornou possível certo equilíbrio da correlação de forças no país, desfaz-se rapidamente, também, a composição de forças que deu sustentação a este projeto. 


\section{REFERÊNCIAS BIBLIOGRÁFICAS}

BALTAR, Ronaldo. A reconstrução do discurso sobre o 'Brasil Moderno' e a idéia de 'Desenvolvimento' pós-transição democrática. In: Ciências Sociais na atualidade. $1^{a}$ ed. São Paulo: Paulus, 2009, p. 89-109.

BOITO JR, Armando. A hegemonia neoliberal no governo Lula. In: Crítica Marxista. Rio de Janeiro, v. 17, 2003, p 9-35

BOITO JR, Armando. As bases políticas do neodesenvolvimentismo. Trabalho apresentado na edição de 2012 do Fórum Econômico da FGV / São Paulo. disponível em: http:// sistema.bibliotecas.fgv.br/.

BOITO JR, Armando. O lulismo é um tipo de bonapartismo? Uma crítica às teses de André Singer. In: Critica Marxista. São Paulo, v. 37, pp. 171-181, 2013.

BOITO JR., Armando. A crise política do neodesenvolvimentismo e a instabilidade da democracia. In: Crítica Marxista n. 42, maio 2016.

BRAGA, Ruy. A política do precariado: do populismo à hegemonia lulista. São Paulo: Boitempo, 2012.

BRESSER-PEREIRA, Luiz Carlos; DINIZ, Eli. Empresariado industrial, democracia e poder político. In: Novos estudos - CEBRAP. São Paulo, n. 84, 2009.

BRESSER-PEREIRA, Luiz Carlos. O governo Dilma frente ao "tripé macroeconômico" e à direita liberal e dependente. In: Novos estudos - CEBRAP, n. 95, São Paulo, Março 2013.

PACCOLA, Marco Antonio Bestetti. Política econômica e industrialização no Brasil. Saarbrücken: Novas edições acadêmicas, 2016.

POULANTZAS, Nicos. Poder político e classes sociais. São Paulo: Martins Fontes, 1977. POULANTZAS, Nicos. O Estado, o poder, o socialismo. Rio de Janeiro: Graal, 1985.

SAAD FILHO, Alfredo. Overthrowing Dilma Rousseff: It's class war, and their class is winning, 2016. Disponível em: https://www.opendemocracy.net/democraciaabierta/ alfredo-saad-filho/overthrowing-dilma-rousseff Acessado em: 09/08/2017.

SAMPAIO JR, Plínio de Arruda. Desenvolvimentismo e neodesenvolvimentismo: tragédia e farsa. In: Serv. Soc. Soc., São Paulo, n. 112, out./dez. 2012.

SINGER, André Vitor. Os sentidos do lulismo: reforma gradual e pacto conservador. São Paulo: Companhia das Letras, 2012.

SINGER, André Vitor. Classes e ideologias cruzadas. In. Novos Estudos Cebrap. Novembro, 2013.

SINGER, André Vitor. Cutucando onças com varas curtas: o ensaio desenvolvimentista no primeiro mandato de Dilma Rousseff (2011-2014). In. Novos Estudos, n. 102, Julho 2015. SINGER, André Vitor. A (falte de) base política para o ensaio desenvolvimentista. In. SINGER, André; LOUREIRO, Isabel. As contradições do Lulismo. 1ªd. São Paulo: Boitempo, 2016, p. 21-55. 